\title{
FRUTOS SILVESTRES (SOLANÁCEAS) DE LA CUENCA DEL RÍO CHILLÓN, PROVINCIA DE CANTA, LIMA - PERÚ
}

\section{WILD FRUITS (SOLANACEAE) FROM THE CHILLÓN RIVER BASIN, PROVINCE OF CANTA, LIMA - PERU}

\author{
Graciela Vilcapoma Segovia ${ }^{1}$
}

\begin{abstract}
Resumen
Se realizó el estudio taxonómico de las especies silvestres de solanáceas, cuyos frutos consumen los campesinos de las 22 comunidades campesinas de la cuenca media y alta del río

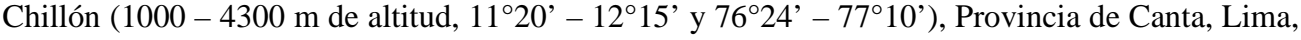
Perú. Se han determinado 11 especies con frutos silvestres comestibles de la Familia Solanaceae: 4 especies de Jaltomata, 4 especies de Salpichroa y 1 especie de los géneros: Lycianthes, Lycopersicon y Physalis. En la cuenca se han colectado en total 22 especies silvestres con frutos comestibles: el 50\% corresponde a las Solanaceae, el $27.3 \%$ a las Cactaceae, el $22.7 \%$ a las Familias: Caricaceae, Passifloraceae, Rosaceae, Asclepiadaceae y Liliaceae.

Palabras clave: Frutos silvestres, Solanaceae, Canta, Perú
\end{abstract}

\begin{abstract}
A taxonomic study was made on wild fruits from the Solanaceae family that are consumed by local inhabitants of 22 communities from the middle and upper Chillon river basin (1000 to 4300 meters of altitudes, $11^{\circ} 20^{\prime}-12^{\circ} 15^{\prime}$ and $76^{\circ} 24^{\prime}-77^{\circ} 10^{\prime}$ ), Province of Canta, Lima, Peru. 11 species with edible fruits of the Solanaceae Family have been registered: 4 species belong to Jaltomata , 4 species to Salpichroa and 1 species to Lycianthes, Lycopersicon and Physalis. In the river basin 22 species with edible wild fruits have been reported: $50 \%$ correspond to Solanaceae, $27.3 \%$ to Cactaceae and $22.7 \%$ to the following Families Caricaceae, Passifloraceae, Rosaceae, Asclepiadaceae and Liliaceae.
\end{abstract}

Key words: Wild fruits, Solanaceae, Canta, Peru

\section{Introducción}

Al realizarse el estudio de la composición florística de la cuenca del río Chillón (1986 - 2000), se registraron 22 especies de frutos silvestres que consumen los campesinos de las 22 comunidades campesinas de la cuenca media y alta del río Chillón. Estos frutos pertenecen a las Familias: Cactaceae, Caricaceae, Passifloraceae, Rosaceae, Asclepiadaceae, Solanaceae y Liliaceae.

En este trabajo se realizó el estudio taxonómico de las especies silvestres de Solanaceae cuyos frutos son comestibles.

Son objetivos de este trabajo:

- Determinar, describir e ilustrar las especies silvestres de Solanaceae con frutos comestibles de la cuenca del Chillón.

- Indicar la distribución geográfica, fenología y nombres comunes de las especies estudiadas.

- Recomendar el estudio de los componentes químicos de los frutos más apreciados por los campesinos para conocer su valor alimenticio. Ya se ha estudiado Physalis peruviana L. "capulí” o “aguaymanto” (Sur del Perú). El “capulí” es fuente de provitamina A (300 UI por 100 gr.), vitamina C y complejo B (Tiamina, Niacina y Vitamina B12, Brack (1999). El “capulí” se consume como fruta y en mermelada. Actualmente esta especie se cultiva debido a la demanda de sus frutos en el mercado.

\section{Área de estudio}

La zona estudiada corresponde a la cuenca media y alta del río Chillón, comprendida entre los 1000 $4500 \mathrm{~m}$. de altitud. Se ubica entre las coordenadas $11^{\circ} 20^{\prime}-12^{\circ} 15^{\prime}$ Latitud Sur y $76^{\circ} 24^{\prime}-77^{\circ} 10^{\prime}$ Longitud Oeste, abarca un área de $2444 \mathrm{Km}^{2}$ (ONER, 1975). Las aguas del río discurren por la vertiente occidental del Pacífico y desembocan al norte de la ciudad de Lima. La cuenca del Chillón, políticamente pertenece a la Provincia de Canta, Región Lima. El área geográfica incluye a 22 comunidades campesinas que pertenecen a 7 Distritos de la Provincia de Canta: Arahuay, Canta, Huamantanga, Huaros, Lachaqui, Santa Rosa de Quives y San Buenaventura (Figura 1a).

\section{Material y método}

Las colectas y observaciones se realizaron en las diferentes estaciones del año, se iniciaron en el año 1986 y concluyeron en el 2004. En Marzo, Abril y Mayo se intensificaron las colectas porque en estos meses las plantas están con flores y frutos. La técnica para colectar fue la convencional (Smith, 1971). Las 
colectas se realizaron de manera aleatoria y a diferentes altitudes de ambas márgenes del río Chillón, entre los 1000 - 4500 m de altitud. Los nombres comunes de las plantas y sus usos se averiguaron en las localidades donde fueron colectadas.

Las especies se determinaron comparando con los Tipos nomenclaturales que se conservan en el Herbario del Departamento Académico de Biología de la Universidad Nacional Agraria La Molina (MOL), Lima - Perú también se consultó las especies identificadas que se conservan en el Herbario de la Universidad Nacional Mayor de San Marcos (USM), Lima - Perú. Asimismo se consultó con los especialistas: Thomas Mione (Biological Sciences, Central Connecticut, USA), Shirley Keel (New Cork Bot. Gard., USA) y William G. D’Arcy (Missouri Bot. Gard. USA)

Esta colección está en una base de datos debidamente codificada y se conserva en el Herbario MOL.

\section{Resultados}

En la cuenca media y alta del río Chillón se han determinado 11 especies silvestres de Solanáceas, cuyos frutos consumen los campesinos de las localidades situadas a ambas márgenes del río Chillón. Se describen e ilustran las especies determinadas, se indica su distribución geográfica, fenología y nombres comunes.

\section{Descripción de las especies determinadas}

Jaltomata aspera (Ruiz \& Pavon) Mione \& F.G. Coe Figura 1.

Sinónimo: Atropa aspera Ruiz \& Pavon

Hebecladus asperus (Ruiz \& Pavón) Miers

Hierba o sufrútice, 30-60 cm de altura. Tallo ramificado, decumbente, folioso, con tricomas rígidos esparcidos. Hojas alternas, pecíolos $1-2 \mathrm{~cm}$ de long., láminas ovadas, $3.5-9 \mathrm{~cm}$ de largo por $2.5-6.5 \mathrm{~cm}$ de ancho, penninervia, bordes usualmente enteros, base algo cuneada, ápice agudo. Flores axilares, solitarias, pedúnculos $1-1.3 \mathrm{~cm}$ de long.; pedicelo articulado, $1.5-1.7 \mathrm{~cm}$ de long. Cáliz rotáceo, 5lobulado, lóbulos agudos, acrescentes en el fruto. Corola crateriforme-rotácea, verdoso-amarillenta, 3 3.8 cm de diámetro, 5-lobulada, lóbulos cortos (3-4 $\mathrm{mm})$. Estambres 5, $7-7.3 \mathrm{~mm}$ de long.; filamentos glabros insertos en la base de la corola, anteras $3 \mathrm{~mm}$ de largo, ventrifijas, dehiscencia longitudinal. Disco nectarífero rojo, de mayor diámetro que el ovario. Ovario súpero, elipsoide, $4 \mathrm{~mm}$ de largo, glabro; estilo $15 \mathrm{~mm}$, estigma claviforme. Baya globosa, amarillento-verdosa, $1-1.5 \mathrm{~cm}$ de diámetro, subinclusa en los sépalos acrescentes.
Distribución geográfica.- especie de la flora de los Departamentos de La Libertad, Lima y Arequipa, distribuida entre $500-2550 \mathrm{~m}$ de altitud (Knapp et al., 2006). En el Chillón se colectó en Puruchuco entre 1800 - $2650 \mathrm{~m}$ de altitud, en suelos arenosoarcilloso con arbustos caducifolios. También se ha colectado en las lomas de Asia (Cañete). Especie ya extinguida para la flora de la Provincia de Lima.

Flores en Febrero - Marzo, frutos maduros en Abril.

Nombre común: “chucrume” (Apan y Puruchuco)

Jaltomata bicolor (Ruiz \& Pavon) Mione \& M. Nee Figura 2

Sinónimo: Atropa bicolor Ruiz \& Pavon Hebecladus bicolor (Ruiz \& Pavón) Miers

Arbusto erguido, glabro, 1 - $50 \mathrm{~m}$ de altura. Tallo pardo-rojizo, ramificado, folioso. Hojas alternas, pecíolos $0.8-2.5 \mathrm{~cm}$ de longitud; láminas subrotundas, ovadas, ovado-oblongas, $4-9.5 \mathrm{~cm}$ de largo por 3-5 cm de ancho, atenuada en la base, ápice águdo o ligeramente acuminado, bordes subenteros, penninervia, puberulenta. Flores nutantes, pedúnculos axilares, 1.5-2 cm de longitud; 2-4 flores en cimas umbeliformes; pedicelos 1-2 cm de long. Cáliz rotáceo, 5-lobulado, lóbulos agudos, reflejos. Corola tubulosa, $2.5-3 \mathrm{~cm}$ de largo por $1 \mathrm{~cm}$ de diámetro, densamente pilosa, violáceo-purpúrea, 5-lobulada, lóbulos verdosos, glabrescentes, decumbentes, acuminados, intercalando con otros 5 dientes muy diminutos. Estambres 5, exsertos, insertos en la base de la corola; filamentos filiformes, pilosos en la base; anteras sagitadas, azulinas, ventrifijas, dehiscencia longitudinal. Disco nectarífero del mismo diámetro que el ovario. Ovario súpero, subgloboso, lobulado, 3 $\mathrm{mm}$ de diámetro, glabro; estilo filiforme, exserto; estigma capitado. Baya esférica comprimida en los polos, 1 - $1.5 \mathrm{~cm}$ de diámetro, anaranajada. Semillas reniformes, diminutas, pardo-rojizas, glabras.

Distribución geográfica.- arbusto de la flora de los departamentos de Ancash, Lima y Huancavelica. En el Chillón se colectó en Arahuay, Canta, Huaros, Huamantanga, Lachaqui y San Buenaventura, entre los 2600 - $3600 \mathrm{~m}$ de altitud, en bordes de caminos y de cultivos, prefiere terrenos arcillosos y secos.

Flores en Febrero - Marzo, frutos maduros Abril Mayo.

Nombre común: “antarupa” (Canta), "guayaco" (Arahuay), “antayroma” (Lachaqui), "shucullmay” (Huamantanga), “capulí” (Huaros).

\section{Jaltomata dentata (Ruiz \& Pavon) Benitez}

Figura 3

Sinónimos: Atropa dentata (Ruiz \& Pavon) Sprengel Saracha dentata Ruiz \& Pavon

Hierba perenne, 30 - $60 \mathrm{~cm}$ de altitud, cáudex perenne, 8 - $10 \mathrm{~cm}$ de largo. Tallo decumbente, 
delgado, puberulento, ramas foliosas, las jóvenes pubescentes, tricomas simples. Hojas con pecíolos 3-8 cm de longitud; láminas ovadas o romboides, 2.5 4(6) $\mathrm{cm}$. de largo por $2-3 \mathrm{~cm}$ de ancho, decurrente en un tercio o mitad del peciolo, ápice águdo, bordes enteros, 5 - 6 lobulados o diminutamente dentados, penninervias, puberulentas en ambas caras. Inflorescencia axilar, cimas umbeliformes, 3-6 (10) flores, pedunculadas, pedúnculos reducidos (3-5 mm de longitud); pedicelos 5-12 mm de longitud. Cáliz rotáceo, puberulento, 5-lobulado, lóbulos agudos y diminutos, acrescentes y reflejo en el fruto. Corola crateriforme, 7 - $8 \mathrm{~mm}$ de largo por $10 \mathrm{~mm}$ de diámetro, ligeramente violácea (lila) con 5 manchitas verdes en la base, densamente pubescentes, 5 lobulada, lóbulos agudos muy diminutos, con una vena tenue para cada lóbulo. Estambres inclusos; filamentos capilares, 3-4 mm de longitud, verdes, glabros; anteras cordadas, ventrifijas, dehiscencia longitudinal. Disco nectarífero de mayor diámetro que el ovario. Ovario súpero, globoso, diminuto; estilo exserto; estigma capitado. Baya globosa, de $7-10 \mathrm{~mm}$ de diámetro, anaranjada. Semillas subreniformes, diminutas.

Distribución geográfica.- hierba de la flora del Departamento de Lima, distribuida entre 2600 3500 m de altitud en las cuencas del Chillón y Rímac. También está citada para la flora de Venezuela. En la cuenca del Chillón esta especie es frecuente en Arahuay, Canta, Huamantanga, Huaros, Lachaqui y San Buenaventura, se colectó en laderas arcillosopedregosas con arbustos perennes, en los bordes de caminos y al pie de cercos. Son las primeras en retoñar con las lluvias veraniegas, forma grandes colonias cuando la vegetación herbácea aún no ha desarrollado. Flores en Diciembre - Febrero, frutos maduros Abril - Mayo.

Nombre común: “shucullmay” (Lachaqui).

Jaltomata propinqua (Miers) Mione \& M. Nee Figura 8.

Sinónimo: Saracha propinqua Miers

Sufrútice o arbusto, $0.9-1 \mathrm{~m}$ de alto. Tallo erguido, cilíndrico, pardo-rojizo, ramas divaricadas, foliosas. Las ramas jóvenes, pecíolos, pedicelos y cáliz densamente pubescentes, tricomas glandulosos. Hojas alternas, pecíolo $1-2.8 \mathrm{~cm}$ de long., láminas ovadas, 4.5 - $9.5 \mathrm{~cm}$ de largo por 2.5 - $6 \mathrm{~cm}$ de ancho, base desigualmente cuneada o redondeada, ápice agudo, bordes enteros o lobulados, puberulenta en ambas caras. Inflorescencia axilar, umbeliforme de 6 7 flores, pedúnculos 1.2 - $1.6 \mathrm{~cm}$ de long.; pedicelos filiformes, $1-1.5 \mathrm{~cm}$ de long., hasta 2 en el fruto. Cáliz subrotáceo, 5-lobulado, lóbulos agudos, reflejos en el fruto. Corola rotáceo-campanulada, ventricosa, 2 - $2.2 \mathrm{~cm}$ de diámetro, violáceo oscura en la base y lóbulos más claros, 5-lobulada, lóbulos 7 - $8 \mathrm{~mm}$ de largo, acuminados, alternando con 5 dientes diminutos, algo cuculados. Estambres 5, inclusos o subexsertos; filamentos 1.3 - $1.6 \mathrm{~cm}$ de long., densamente villosos, violáceo intenso, el tercio superior filiforme y glabro; anteras cordiformes, 2 - 3 $\mathrm{mm}$, ventrifijas, dehiscencia longitudinal. Disco nectarífero casi de igual diámetro que el ovario. Ovario súpero subgloboso, $2 \mathrm{~mm}$ de diámetro, glabro; estilo filiforme, $1.5-1.7 \mathrm{~cm}$ de largo, exsertos; estigma capitado. Baya globosa, de $7-10 \mathrm{~mm}$ de diámetro, anaranjada o amarilla, poco jugosa. Semillas subreniformes, pardo-amarillentas.

Distribución geográfica.- especie de la flora del Departamento de Lima, de las cuencas del Chillón y Rímac. En el Chillón es abundante en la cuesta a Puruchuco y en los alrededores de la población de Arahuay, entre $1800-2600 \mathrm{~m}$ de altitud. Prefiere hábitat pedregoso-arcilloso con arbustos caducifolios. Flores en Febrero - Marzo, frutos maduros en Abril. Nombre común: “shucrume” (Arahuay).

\section{Lycianthes lycioides (L.) Hassler}

Figura 5.

Sinónimo: Solanum lycioides L.

Arbusto hasta 1 - $50 \mathrm{~m}$ de altura. Tallo nudoso, glabrescente, ramas foliosas con el ápice punzante, espiniforme. Hojas alternas en fascículos, pecíolos 2 5 mm de longitud; láminas elípticas u obovadas, 1.2 $4 \mathrm{~cm}$ de largo por $0.8-1.8 \mathrm{~cm}$ de ancho, base cuneada, ápice agudo u obtuso, bordes enteros, penninervia, glabra en ambas caras. Flores axilares, solitarias, algunas veces hasta 4 flores; pedicelos delgados, $1.5-2.3 \mathrm{~cm}$ de long., hasta $3 \mathrm{~cm}$ en el fruto. Cáliz ciatiforme, $3 \mathrm{~mm}$ de largo, membranoso con bandas longitudinales verde-oscuras, 5-dentado, dientes diminutos, subulados, alternan con otros más pequeños. Corola rotácea, $1-1.5 \mathrm{~cm}$ de diámetro, azul- violácea, centro amarillo, estrella blanquecina, ligeramente 5-lobulada. Estambres 5, desiguales, 3 más largos (1.5 - 2 mm de longitud) y 2 más cortos (0.6 - $1.3 \mathrm{~mm}$ de longitud) con una giba en la base; filamentos glabros; anteras linear-emarginadas, 2 - 3 $\mathrm{mm}$ de largo, anaranjadas, subiguales, basifijas, dehiscentes por poros apicales, introrsos. Disco nectarífero ausente. Ovario súpero, ovoide, $1.5-2$ mm de largo, glabro; estilo 3 - 4 mm de longitud, con el ápice curvado hacia los estambres más cortos; estigma bilobulado. Baya globoso-deprimida, anaranjada, $1-1.5 \mathrm{~cm}$ de diámetro, cada lóculo con 3 - 4 pirenas (esclerosomas), éstos con una semilla diminuta.

Distribución geográfica.- arbusto de la flora de los Departamentos de Amazonas, Cajamarca, Lambayeque, La Libertad, Ancash, Huanuco, Lima, Junín, Ayacucho, Arequipa y Cusco, distribuida entre 1000 - 4000 m de altitud (Brako \& Zarucchi, 1993). En la cuenca del Chillón se ha colectado en : 
Arahuay, Huamantanga, Huaros, Lachaqui y San Buenaventura, entre 1800 - 3300 m de altitud. Esta especie constituye la vegetación arbustiva de las laderas rocosas, bordes de caminos y montes ribereños.

Flores en Febrero, Marzo y Abril; frutos maduros Abril y Mayo.

Nombre común: “chucluma” (Canta).

\section{Lycopersicon pimpinellifolium (Juslenius) Miller}

Figura 6.

Sinónimo: Solanum pimpunellifolium Juslenius

Hierba anual, postrado-ascendente. Tallo ramificado, puberulento o glabrescente. Hojas alternas, imparipinnadas, hasta $13 \mathrm{~cm}$ de largo; peciolo $1-2 \mathrm{~cm}$ de longitud, a menudo sin pseudoestípulas; 3 pares de foliolos mayores, 2 - 5 foliolos menores, peciolados, subrotundos u ovados; foliolos mayores con peciolulos de $4-7 \mathrm{~mm}$ de longitud, ovados, $1.2-2 \mathrm{~cm}$ de largo por $0.9-1.2$ $\mathrm{cm}$ de ancho, foliolo terminal ligeramente mayor, base cordada y asimétrica, ápice agudo, bordes subenteros, haz glabresecente, envés puberulento. Cimas bifurcadas, racemiformes, hasta $15 \mathrm{~cm}$ en el fruto, puberulentas, más de 10 flores con pedicelos filiformes, $10-14 \mathrm{~mm}$ de longitud, articulado a $3 \mathrm{~mm}$ del cáliz. Cáliz pubescente, 5-partido, lóbulos lanceolado-acuminados, $2.5-3 \mathrm{~mm}$ de largo, acrescente y reflejo en el fruto. Corola rotáceoestrellada, 10 - 12 mm de diámetro, amarillo limón, profundamente 5-partida, lóbulos lanceolados largamente atenuados hacia el ápice. Estambres 5; anteras subsésiles con apéndices apicales, dorsalmente puberulenta; columna estaminal $5-7 \mathrm{~mm}$ de largo, recta. Disco nectarífero ausente. Ovario súpero, glabro; estilo ligeramente exserto. Baya globosa, anaranjada, 0.9-1.2 cm de diámetro, numerosas semillas. Semillas ovoides o subreniformes, amarillentas, lisas, glabras.

Distribución geográfica.- hierba de las vertientes occidentales, desde Tumbes hasta Arequipa, distribuida entre 0 - $1500 \mathrm{~m}$ de altitud. En la cuenca del Chillón se ha colectado en Santa Rosa de Quives, entre los 700 - $900 \mathrm{~m}$ de altitud. Es frecuente en bordes de cultivos o invadiendo éstos, orillas de acequias y monte ribereño. Esta es la única especie de la cuenca baja que asciende hasta $1250 \mathrm{~m}$ de altitud.

En la costa florece en Setiembre-Noviembre, frutos maduros en Diciembre-Enero. También se encuentran con flores en los montes ribereños a $1200 \mathrm{~m}$ de altitud en los meses de Abril y Mayo.

Nombre común: “tomatillo” ( Santa Rosa de Quives).

Physalis peruviana L.

Figura 7.

Sinónimo: Physalis tomentosa Medikus
Hierba anual, 0.6 - $1.0 \mathrm{~m}$ de altura, densamente pubescente, excluyendo a la corola. Tallos erguidos o extendidos, flexuosos, difusamente ramificados, foliosos. Hojas alternas, peciolo $1.5-3 \mathrm{~cm}$ de longitud, pilosos; láminas ovadas u ovado-cordadas, 5 - $12 \mathrm{~cm}$ de largo por $4-10 \mathrm{~cm}$ de ancho, base cordiforme, ápice cortamente acuminado, bordes enteros o irregularmente dentado-lobulado, subtomentosos en ambas caras. Flores axilares, solitarias; pedúnculo 7-10 mm de longitud. Cáliz campanulado, pubescente, 5-dentado, dientes subiguales, acuminados. Corola rotáceo-campanulada, 15 - 17 mm de diámetro, amarilla o anaranjada con 5 manchas pardo-oscuras. Estambres 5, inclusos, insertos en la base del tubo de la corola; filamentos filiformes, 4 - $5 \mathrm{~mm}$ de longitud, glabros; anteras ovoides, $3 \mathrm{~mm}$ de largo, azul-purpúreas, basifijas, dehiscencia longitudinal. Ovario súpero, cónico, $3 \mathrm{~mm}$ de alto, glabro, numerosos óvulos; estilo $7 \mathrm{~mm}$ de longitud, glabro, ápice engrosado; estigma capitado. Baya esférica, 1.5 - $2 \mathrm{~cm}$ de diámetro, anaranjada, envuelta totalmente por el cáliz acrescente, semillas numerosas. Semillas reniformes, diminutas, pardorojizas, lisas.

Distribución geográfica.- hierba de la flora de las vertientes occidentales y valles interandinos, distribuidas entre 0 - $4500 \mathrm{~m}$. de altitud (Brako \& Zarucchi, 1993). En la cuenca del Chillón esta especie esta casi extinta. Hasta el año 1979 se colectó en Canta (Tambo) y San Buenaventura a $2600-2800$ $\mathrm{m}$ de altitud. Actualmente sólo se ha colectado en Arahuay, en laderas arenoso-arcillosas y bordes de cultivos rotativo. La excesiva colecta de los frutos de esta especie por turistas y otros colectores sería la posible causa de la desaparición de esta hierba en los Distritos de Canta y San Buenaventura, que están situados en la carretera Lima - Cerro de Pasco.

Flores en Marzo - Abril, frutos maduros en Mayo Junio.

Nombre común: “capulí” (Arahuay, Canta, San Buenaventura).

\section{Salpichroa glandulosa (Hooker) Miers}

Sinónimo: Salpichroma glandulosum (Hooker) Dunal

Arbusto tendido o postrado, $0.8-1.0 \mathrm{~m}$ de altura. Tallo anguloso, ramificado, ramas pubescenteglanduloso. Hojas geminadas; pecíolo $7-15 \mathrm{~mm}$ de longitud; láminas cordadas o subcordadas, $1-3 \mathrm{~cm}$ de largo por $1-2.3 \mathrm{~cm}$ de ancho, base cordada, ápice agudo, bordes enteros, ambas caras pubescenteglandulosas. Flores axilares, solitarias, nutantes, pedúnculos filiformes, $9-12 \mathrm{~mm}$ de longitud. Cáliz pubescente-glanduloso, 5-partido, lóbulos sublineares, $8-12 \mathrm{~mm}$ de largo. Corola tubulosoinfundibuliforme, $3.8-4.5 \mathrm{~cm}$ de largo, amarilla, 5lobulada, lóbulos ovados, de bordes flocosos, reflejos. Estambres 5, subexsertos, insertos cerca de la garganta 
de la corola; filamentos libres, 2 - $3 \mathrm{~mm}$. de longitud; anteras linear-oblongas, $3 \mathrm{~mm}$. de largo, dorsifijas, dehiscencia longitudinal. Disco nectarífero de mayor diámetro que el ovario. Ovario súpero, cónico, 4 - 5 $\mathrm{mm}$. de alto, glabro; estilo filiforme, exserto; estigma capitado. Baya ovoide-oblonga, $2.5-3.5 \mathrm{~cm}$. de largo x $1.5 \mathrm{~cm}$. de diámetro, azul oscuro, semillas numerosas. Semilla elíptica, comprimida, diminuta, glabra, testa punteada.

Distribución geográfica.- arbusto de la flora de los Departamentos de Pasco, Lambayeque, Ancash, Junín, Lima, Ayacucho, Huancavelica y Cusco, distribuida entre 3000 - $4500 \mathrm{~m}$. de altitud (Brako \& Zarucchi, 1993). En la cuenca del Chillón esta especie es muy escasa, se colectó en Canta y Lachaqui, a 4000 - 4 $500 \mathrm{~m}$. de altitud, en límites con el Departamento de Junín y la Provincia de Huarochirí. Arbusto que constituye la flora de los roquedales de la puna.

Flores en abril - mayo, frutos maduros en junio julio.

Nombre común: "pepinillo” (Canta), “ayanata” (Lachaqui)

\section{Salpichroa microloba Keel}

Figura 8.

Sufrútice o arbusto, $1 \mathrm{~m}$ o más de altura. Tallo alado-dentado, pardo-rojizo, auriculado, con ramas foliosas, flexuosas, puberulentas. Hojas geminadas, pecíolo 7 - $12 \mathrm{~mm}$ de long.; láminas cordadas u ovado-cordadas, $1.5-3 \mathrm{~cm}$ de largo por $1-2.5 \mathrm{~cm}$ de ancho, base cordada, ápice agudo, bordes enteros, haz verde oscuro, envés verde claro, densamente puberulento en ambas caras. Flores axilares, solitarias, nutantes, pedúnculos $7-10 \mathrm{~mm}$ de long., puberulentos. Cáliz profundamente 5-partido, lóbulos 8 - $10 \mathrm{~mm}$. de largo, subulados, puberulentos. Corola tubulosa, 2.2 - $3 \mathrm{~cm}$ de largo (sin incluir los lóbulos), amarilla, venosa, glabra, 5-lobulada, lóbulos ovados, bordes puberulentos. Estambres 5, inclusos; filamentos 17 - $22 \mathrm{~mm}$ de long., la parte libre 1 - 2 $\mathrm{mm}$, glabro; anteras linear-oblongas, dorsifijas, dehiscencia longitudinal. Disco anular carnoso, ligeramente de mayor diámetro que el ovario. Ovario cónico, 4 - $5 \mathrm{~mm}$ de alto, glabro; estilo 1.8 - $2 \mathrm{~cm}$ de long., algunas veces ligeramente exserto; estigma capitado. Baya ovoide, casi cónica, $2-2.5 \mathrm{~cm}$. de largo por $1-1.3 \mathrm{~cm}$. de diámetro, azul oscura, semillas numerosas. Semillas subredondeadas, comprimidas, pardo-amarillentos, punteadas.

Distribución geográfica.- especie de las vertientes occidentales del Centro del Perú. En la cuenca del Chillón es frecuente entre 3500 - 3900 m de altitud, en Huamantanga, Huaros y Lachaqui, esta última es la localidad del TIPO. Casi siempre asociada a Opuntia subulata (Muehlenpfordt) Engelmann o apoyada sobre muros de piedras.
Flores en Febrero - Abril, frutos maduros Mayo Junio.

Nombre común: “pepinillo” (Canta), “antarupa” (Huaros), “chonchoycomay” (Huamantanga) y “ayanata” (Lachaqui ).

\section{Salpichroa ramosissima Miers}

Figura 9.

Sinónimos: Salpichroa dilatata Dammer Salpichroa uncu Benoist

Arbusto glabro, 1.5 - $2 \mathrm{~m}$ de altura. Tallo cilíndrico con ramas divaricadas, flexuosas, foliosas. Hojas geminadas, pecíolos de 10 - 14 mm de long.; láminas cordadas o cordado-lanceoladas, $2-3.2 \mathrm{~cm}$ de largo por $1.8-2.5 \mathrm{~cm}$ de ancho, base subcordada o truncada, ápice agudo, bordes enteros, envés con nervaduras principales conspicuas, glabra en ambas caras. Flores axilares, solitarias, pedúnculos filiformes, 3 - 14 mm de long. Cáliz 5-partido, lóbulos subulados, $4-5 \mathrm{~mm}$ de largo. Corola tubulosa, ligeramente ensanchada en su mitad superior, garganta estrecha, $1.2-1.5 \mathrm{~cm}$ de largo por $0.5 \mathrm{~cm}$ de diámetro en la mitad del tubo, amarillo-verdosa, glabra, 5-lobulada, lóbulos triangular-lanceolados, divaricados. Estambres 5, inclusos, porción libre 1 - 2 $\mathrm{mm}$, anteras linear-oblongas, dorsifijas, dehiscencia longitudinal. Disco nectarífero carnoso de igual diámetro que el ovario. Ovario súpero, cónico, glabro; estilo $10 \mathrm{~mm}$ de long.; estigma capitado. Baya ovoide, $1.5-2 \mathrm{~cm}$ de largo por $1.2-2 \mathrm{~cm}$ de diámetro, verde claro con halo rojo en la base, numerosas semillas. Semillas reniformes, diminutas, amarillas, glabras, testa granulada.

Distribución geográfica.- arbusto de la flora de los Departamentos de Ancash, Lima, Ayacucho y Arequipa, distribuida entre 2000 - 4500 m de altitud (Brako \& Zarucchi, 1993). En la cuenca del Chillón se colectó en Arahuay, Canta, Huamantanga, Huaros, Lachaqui y San Buenaventura, entre los 2600 - 3400 $\mathrm{m}$. de altitud. Esta planta forma parte de la vegetación arbustiva de las laderas y montes ribereños.

Flores en Febrero - Abril, frutos maduros Abril Mayo.

Nombre común: “pepinillo” (Canta), “callalluma” (Lachaqui).

Salpichroa tristis Miers var. Iehmannii (Dammer) Keel

Figura 10.

Sinónimos: Salpichroma lehmannii Dammer

Sufrútice o arbusto, piloso-hirsuto, 20 - $45 \mathrm{~cm}$ de largo. Tallo postrado, ramas divaricadas, frágiles, foliosas, hirsutas. Hojas geminadas, pecíolos $5-15$ mm de long.; láminas subcordadas o anchamente ovadas, 6 - 10 (15) $\mathrm{mm}$ de largo por 5 - 8(12) $\mathrm{mm}$ de ancho, base truncada, ápice agudo u obtuso, bordes 
enteros, haz pubescente-hirsuto, envés pubescente. Flores axilares, solitarias, con pedúnculos de $3-4$ mm de long. Cáliz hirsuto, 5-partido, lóbulos lineares, de $12 \mathrm{~mm}$ de largo. Corola tubulosa, ligeramente angostada en la mitad, 1.8 - $2.1 \mathrm{~cm}$ de largo ( $\sin$ incluir los lóbulos), amarilla con matices pardo oscuro, finamente pubescente, 5-lobulada, lóbulos lanceolados, 3 - $4 \mathrm{~mm}$ de largo, reflejos. Estambres 5, inclusos, llega hasta la garganta de la corola; porción libre de los filamentos $1-3 \mathrm{~mm}$ de long.; anteras oblongas, 2 - $3 \mathrm{~mm}$ de largo, dorsifijas, dehiscencia longitudinal. Disco nectarífero de igual diámetro que el ovario. Ovario casi ovoide, diminuto, glabro; estilo 15 - 17 mm de long.; estigma capitado. Baya subgloboso-ovoide, $1-1.2 \mathrm{~cm}$ de largo por $0.7-1$ cm de diámetro, semillas numerosas. Semillas diminutas, pardo-amarillentas, glabras.

Distribución geográfica.- especie de la flora de los Departamentos de Cajamarca, Lima, Ayacucho, Huancavelica, Arequipa y Puno, distribuidas entre los 2000 - 4500 m de altitud (Brako \& Zarucchi, 1993). En la cuenca del Chillón se ha colectado en Arahuay, Canta, Huaros y Lachaqui, entre los 3900 - 4500 m de altitud. Constituye la vegetación de los roquedales, casi siempre adherida a las rocas o tapizando las cuevas.

Flores en Abril - Mayo, frutos maduros Junio - Julio. En hábitat húmedo es posible encontrarla con flores hasta Setiembre. En las estaciones secas (no lluviosas), las hojas y flores se reducen considerablemente.

Nombre común: “callalluma”, “frutilla” (Lachaqui).

\section{Discusión}

Sobre frutos silvestres que se comen en la cuenca del Chillón, Vilcapoma (2000) reportó las especies de Cactáceas. En el presente trabajo se dan a conocer las especies de las Solanáceas consumidas como frutas. En el tratamiento taxonómico de estas especies, se considera a Lycianthes (Dunal) Hassler, como género independiente de Solanum L., siguiendo criterios de Hassler (1917), D’ Arcy (1986), Nee (1989) y Hunziker (1992).

Entre los años 1979-1983, Shirley Keel (City University of New York, USA) hizo la revisión de las especies peruanas del género Salpichroa Miers. En esta revisión describió una especie nueva para la flora peruana: Salpichroa microloba Keel, cuyo TIPO de esta fue colectado en Lachaqui - Canta (Keel, 1993 ).

Las especies del género Jaltomata Schlechtendal han sido tratadas por mucho tiempo dentro de los géneros Saracha y Hebecladus. Actualmente muchas especies de Jaltomata tienen basónimos en estos géneros.

El género Saracha fue descrito por Ruiz \& Pavon (1774) en la Flora Peruviana et chilensis. Posteriomente Ruiz \& Pavon (1779) describieron varias especies de Saracha que actualmente son

\section{Jaltomata.}

El género Hebecladus fue fundado por Miers (1845) para incluir algunas especies sufrutescentes y arbustivas con corolas tubulosas e infundibuliformes, que actualmente son Jaltomata. Algunas especies de Hebecladus habían sido descritas incorrectamente por Ruiz \& Pavon (1774) como Atropa (género de las Solanaceas del viejo mundo).

Miers (1849) reconoció que Saracha no es un buen grupo natural y dividió a este género en dos grupos: Saracha R et P. y Poecilocroma Miers, basándose en la estructura floral y en el hábito de las plantas. Miers desacertadamente ubicó al TIPO de Saracha en Poecilocroma. Miers, tuvo varios desaciertos al tratar las especies de Saracha descritas por Ruiz \& Pavon.

Macbride (1962) describe las especies de Jaltomata incluidos en los géneros: Saracha $y$ Hebecladus.

Schlechtendal (1838) fundó el género Jaltomata con una sola especie: Jaltomata edulis Schlechtendal. Al siguiente año Schlechtendal (1839) pasó su única especie al género Saracha, de esta manera Jaltomata fue sinónimo de Saracha. Pero la especie Jaltomata edulis ya había sido descrita por Cavanilles como Atropa procumbens Cav.

Gentry (1973) restableció el género Jaltomata y corrigió el nombre de la especie TIPO: Jaltomata procumbens (Cav.) J. L. Gentry, especie de la flora de México. También transfirió dos especies de Saracha a Jaltomata.

El género Jaltomata ha sido revisado por botánicos como: Gentry (1973-1974), Davis (1980) y Mione (1992) a la fecha, los que han contribuido a esclarecer la taxonomía del género y la historia nomenclatural de Jaltomata y Saracha.

En la Cuenca del río Chillón se ha colectado 4 especies de Jaltomata, cuyos frutos se comen.

Jaltomata aspera (R. et P.) Mione, ya desaparecida para la flora de la Provincia de Lima, en la cuenca del Chillón se encuentra en los flancos interandinos a $1800-2600$ m de altitud; también se ha colectado en las lomas de Asia (Provincia de Cañete).

En este trabajo no se incluye a Jaltomata andersonii Mione, especie citada para Huamantanga por Mione et al., 2004. En el Herbario MOL, el único ejemplar (sin frutos) está colectado para la Provincia de Huarochiri por Mione, Leiva \& Yocher $\mathrm{N}^{\circ} 620$. Es muy posible que esta especie se encuentre sólo en Huamantanga. Jaltomata andersonii es muy afin a Jaltomata aspera, se diferencia de esta última por el pedicelo no artículado, color de la corola y los estambres pubescentes. Fruto no conocido. En el Herbario USM, no existe ningún ejemplar de esta especie. 


\section{Conclusiones}

- La Familia Solanaceae tiene 11 especies silvestres, cuyos frutos son consumidos por las 22 comunidades campesinas de la Provincia de Canta.

- La mayor concentración de estas especies están entre los $2200-3500 \mathrm{~m}$. de altitud. Siendo las más frecuentes Jaltomata bicolor y Jaltomata dentata.

- Las especies más apreciadas por los campesinos son Jaltomata bicolor y Salpichroa microloba, las bayas de estas son jugosas, dulces y agradables. Se recomienda analizar sus componentes químicos.

- Especies escasas en la cuenca: Salpichroa glandulosa y Physalis peruviana. Esta última especie se colectó hasta el año de 1978 en los alrededores de Canta y San Buenaventura, actualmente han desaparecido de estas localidades, solamente se encuentra en Arahuay.

- Lycopersicon pimpinellifolium, es la única especie de la cuenca baja que asciende hasta la cuenca media (540 - 1200 m de altitud).

- Las especies: Salpichroa tristis y Salpichroa glandulosa constituyen la flora de cuenca alta del río Chillón (3 900 - 4500 m de altitud).

\section{Agradecimientos}

La autora expresa su agradecimiento a la Mg. Sc.

Mercedes Flores y a los Biólogos José Alegría y

Arturo Granda por su empeñoso trabajo durante la recolección.

Esta investigación fue financiada por el Fondo

Especial de Desarrollo Universitario (FEDU) de la Universidad Nacional Agraria La Molina.

Literatura citada

Bitter G. 1919. Die Gattung Lycianthes. Abh. Naturw. Ver. Bremen. 24 (2): 292-520, f. 1-5

Brack Egg A. 1999. Diccionario Enciclopédico de Plantas útiles del Perú. Ed. Centro Bartolomé de las Casas, Perú.

Brako L. \& Zarucchi J. 1993. Catálogo de las Angiospermas y Gimnospermas del Perú. Missouri Bot. Gard. 45: 11286.

Davis T. IV. 1980. The generic relationship of Saracha and Jaltomata (Solanaceae) Rhodora. 82: 345-352.

D'arcy W.G. 1979. The Classification of the Solanaceae. En: J.G. Hawkes, R.N. Lester \& A.D. Skelding. The Biology and Taxonomy of the Solanaceae. Linean Soc. Symp. Ser. 7: 3-47.
1986. The calyx in Lycianthes and some other genera. Annals of the Misouri Bot. Garden. 73 (1): 117127.

Gentry J.L. 1973. Restoration of Jaltomata (Solanaceae). Phytologia. 27: 286-288.

Hassler E. 1917. Solanaceae austro-americanae. Ann. Conserv. Jard. Bot. Geneve. 20: 173-189, f. 1-3.

Hunziker A.T. 1979. South American Solanaceae: a Synoptic Survey, Pág 49 - 85. In: Hawkes J.G., Lester R.N. \& Skelding A.D. (Eds). Solanaceae Biology and Taxonomy. Academic Press, London.

Keel S. 1993. A new species and a new combination in Salpichroa (Solanaceae). Novon. 3: 46 - 48.

Knapp S., Spooner D. \& León B. 2006. Solanaceae endémicas del Peru. En: El Libro Rojo de las Plantas Endémicas del Perú. Revista Peruana de Biología. 13 (2): 616 - 618.

Macbride J.F. 1962. Solanaceae in Flora of Peru. Vol. XIII, Part V-B. 1:19-65.

Mione T. \& Coe F.G. 1992. Two new combinations in Peruvian Jaltomata (Solanaceae). Novon. 2: 383-384.

Mione T., Leiva S.\& Yacher L. 2004. Jaltomata andersonii (Solanaceae) : a new species of Perú. Rhodora 106: 118123.

Miers J. 1848. Solanaceae. Prodromus, Vol. XIII.

Miers J. 1845. Contributions to the botany of South America. Lond. Journ. Bot. 4: 319-325 . . 1848. Contribution to the botany of South America. Lond Journ. Bot. 7: 353-359. . 1849 Ann. and Mag. Of Nat. Hist ser. V.3 Pág. 443.

Morton, C. V. 1938. Notes on the genus Saracha. Proc. Biol. Soc. Wash. 51: 75-77.

Ruiz H. \& Pavon J. 1774. Florae Peruvianae et Chilensis Prodromus 31, tab. 34. Facsímile edition 1965.

. 1799. Florae peruvianae Chilensis Prodromus 2: 42, tab. $178 \mathrm{~b}$ Prodromus., Vol 2.

Schlechtendal D. F. L. 1838. Index seminum horto academico halensi. p. 8. académico halensi. p. 8 .

1839. Index seminum horto

Smith C. E. 1971. Preparing herbarium specimens of vascular plants. Agric. Information Bull. 348: 1-29.

Vilcapoma G. 1987. Solanaceae del Valle del Chillón. Boletín de Lima. 52: 63-82.

Vilcapoma G. 2000. Revista QUEPO, Sociedad Peruana de Cáctus y suculentas. Vol. 14: 59-67. 
FRUTOS SILVESTRES (SOLANÁCEAS) DE LA CUENCA DEL RÍO CHILLÓN, LIMA Dciembre 2007

Figuras citadas en el texto.

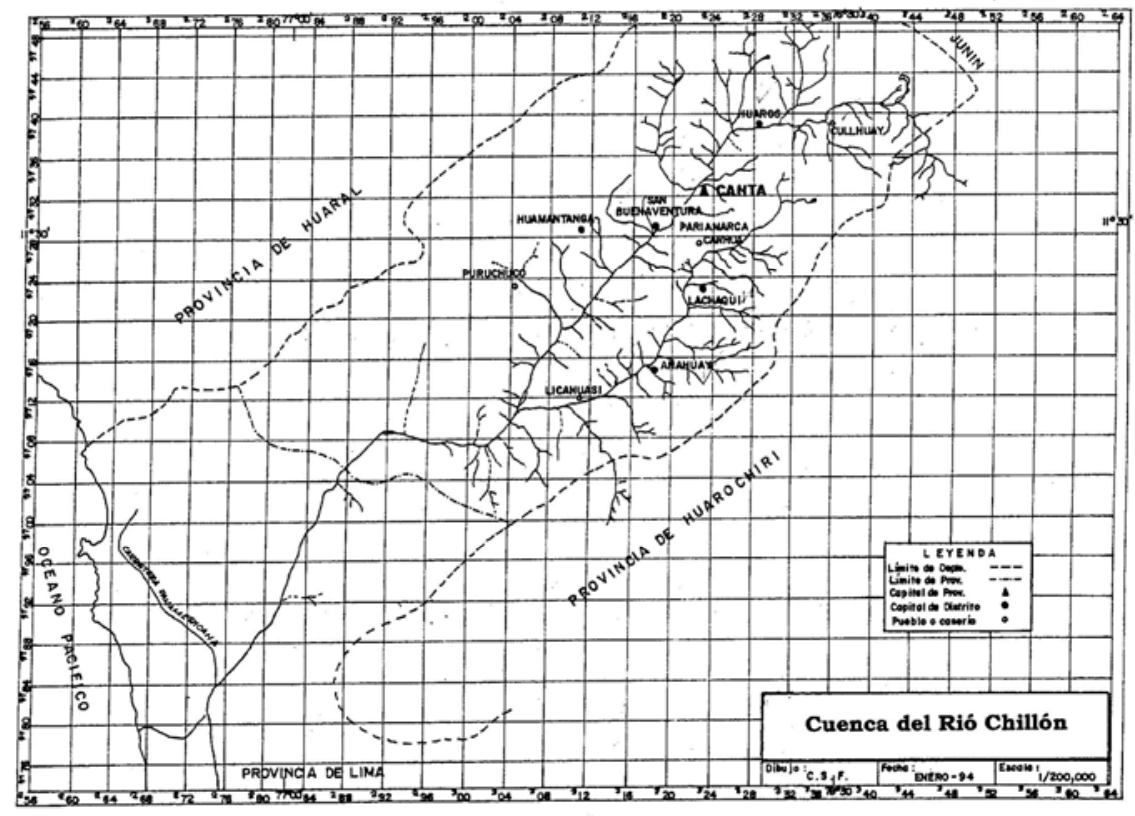

Figura 1a. Mapa de ubicación de la zona estudiada, cuenca media y alta del río Chillón

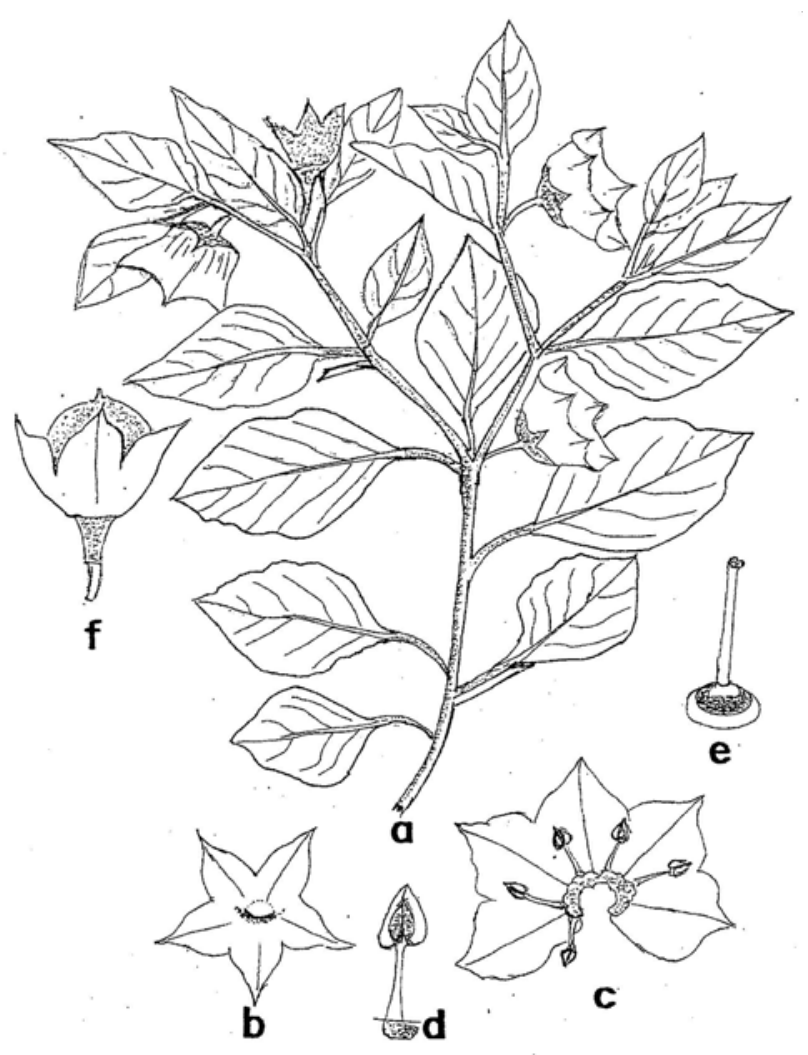

Fig. 1 Jaltomata aspera (R. \& P.) Mione

a) rama florida $(x 0.5)$; b) cáliz $(x 1)$; c) corola desplegada $(x 1) ;$ d) estambre $(x 2)$; e) pistilo ( $(x 1.5)$; f) baya ( $x 1)$.

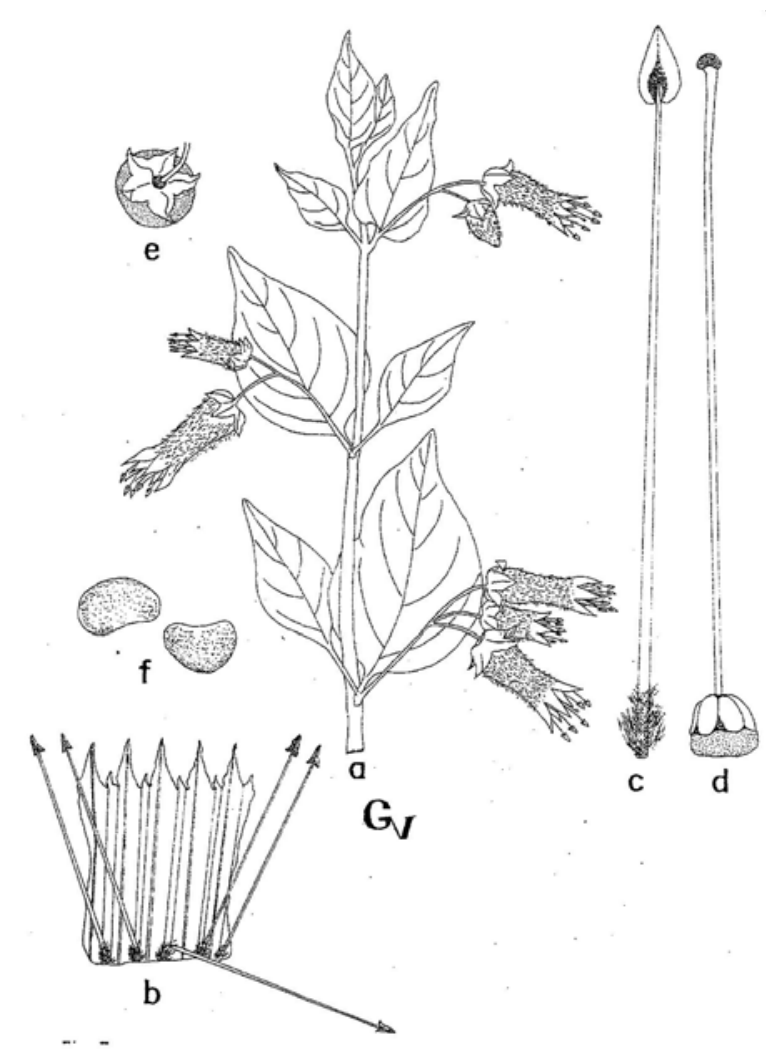

Fig. 2 Jaltomata bicolor (R. \& P.) Mione \& Nee

a) rama florida ( $x 1)$; b) corola desplegada $(x 2)$; c) estambre (x5); d) pistilo (x5); e) fruto ( $x 1)$; f) semillas $(x 10)$. 


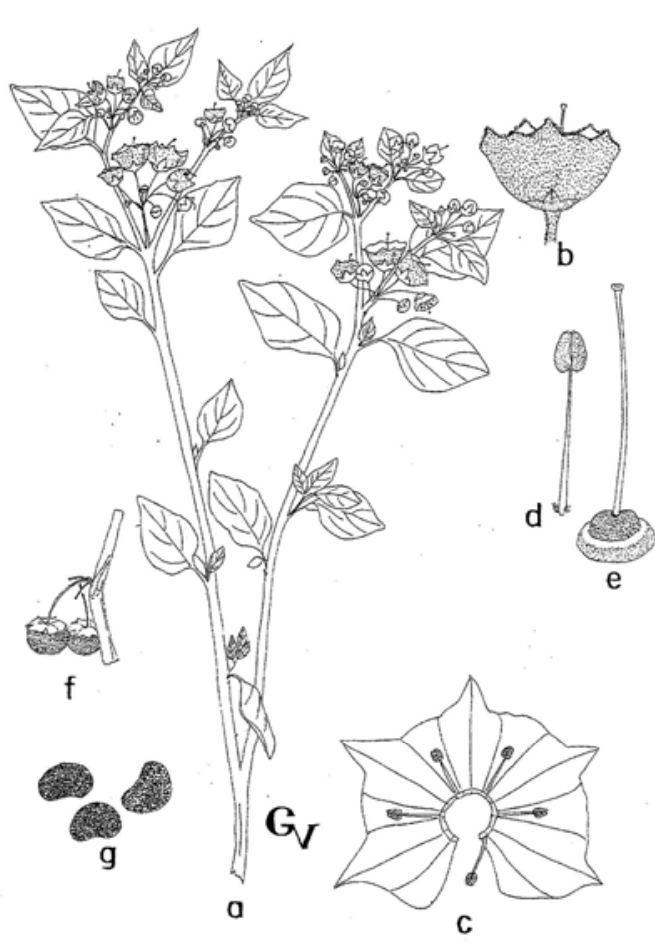

Fig. 3 Jaltomata dentata (R. \& P.) Benitez

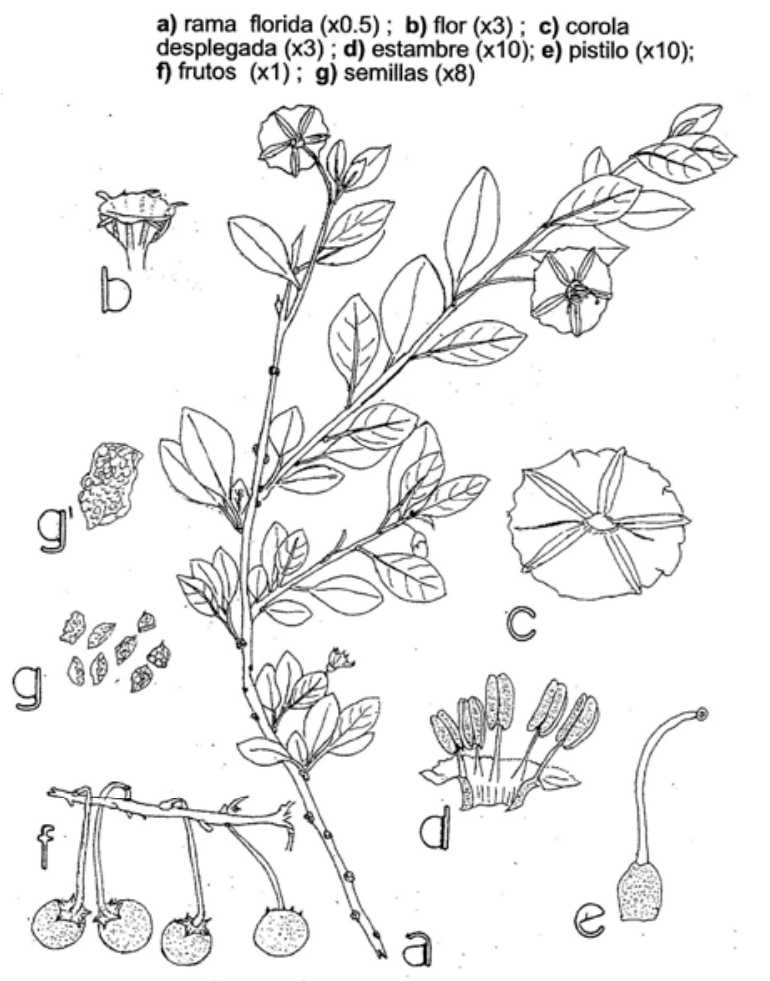

Fig. 5 Lycianthes lycioides (L.) Hassler

a) rama con flores $(x 1)$; b) cáliz (x5); c) corola extendida (x2); d) estambres (x5); e) pistilo (x5): f) bayas $(x 1) ;$ g) semillas $\left.(x 1) ; g^{\prime}\right)$ semilla( $(3 x)$.

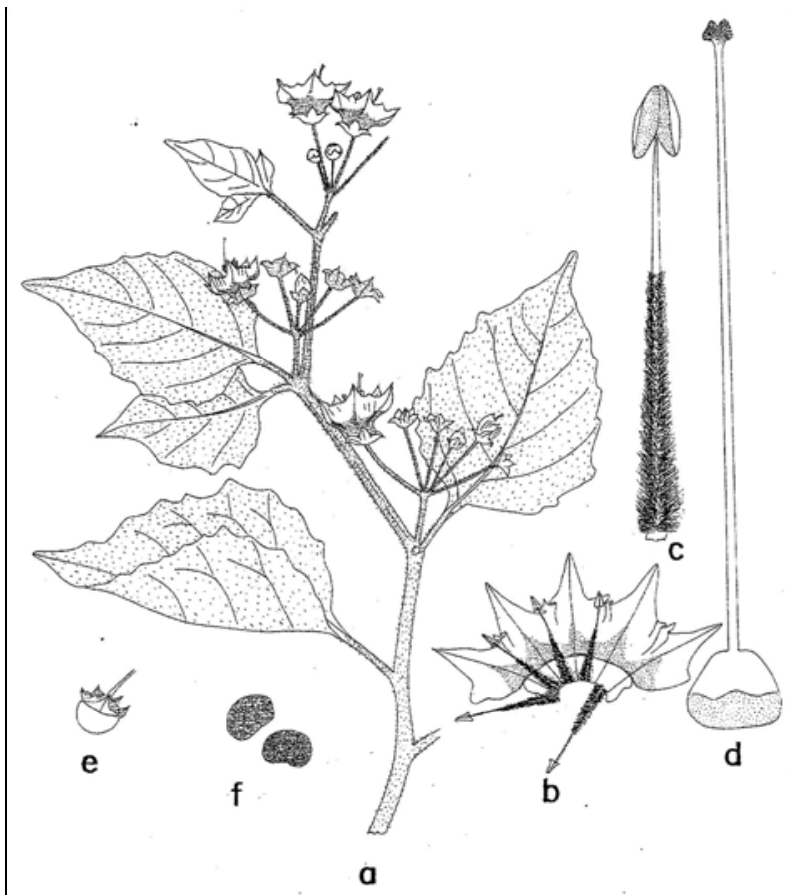

Fig. 4 Jaltomata propinqua (Miers) Mione \& Nee

a) rama florida $(x 5)$; b) corola desplegada $(x 2)$; c) estambre (x8); d) pistilo (x5); e) fruto (x1); f) semillas.

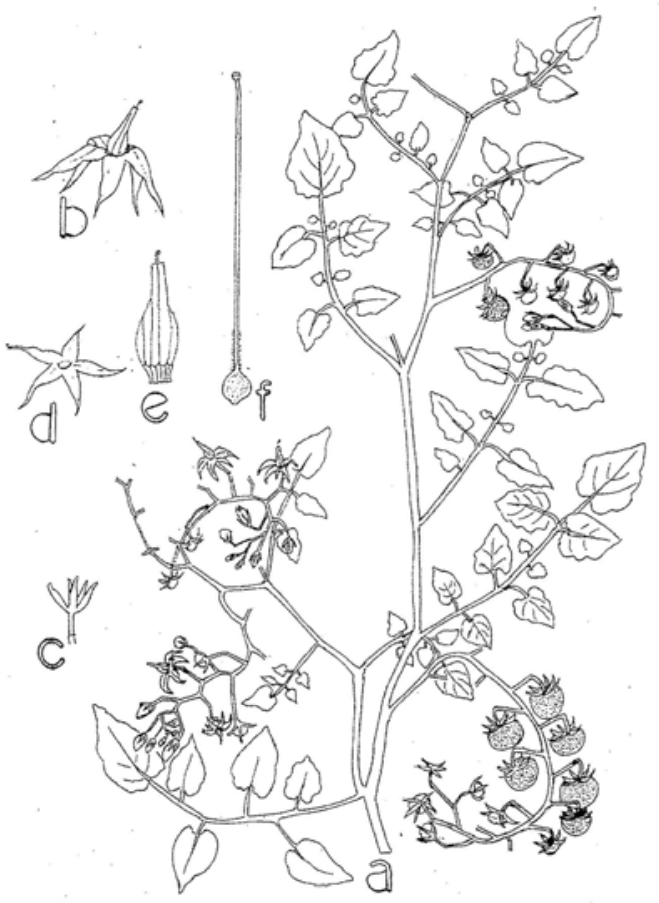

Fig. 6 Lycopersicon pimpinellifolium (Jusl.) Miller

a) rama con flores $y$ frutos $(x 1)$; b) flor $(x 5)$; c) cáliz $(x 2)$; d) corola extendida $(x 2)$; e) columna estaminal $(x 3)$; f) pistilo ( $x 7$ ) 


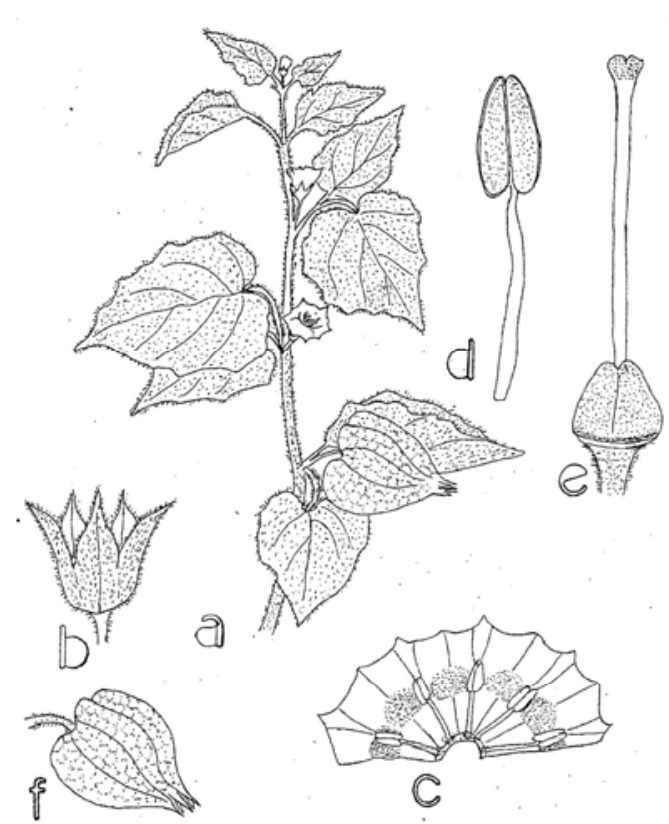

Fig. 7 Physalis peruviana L.

a) rama florida (x1); b) cáliz (x5); c) corola abierta (x5); d) estambre (x10); e) pistilo (x10); f) frutos $(x 1)$

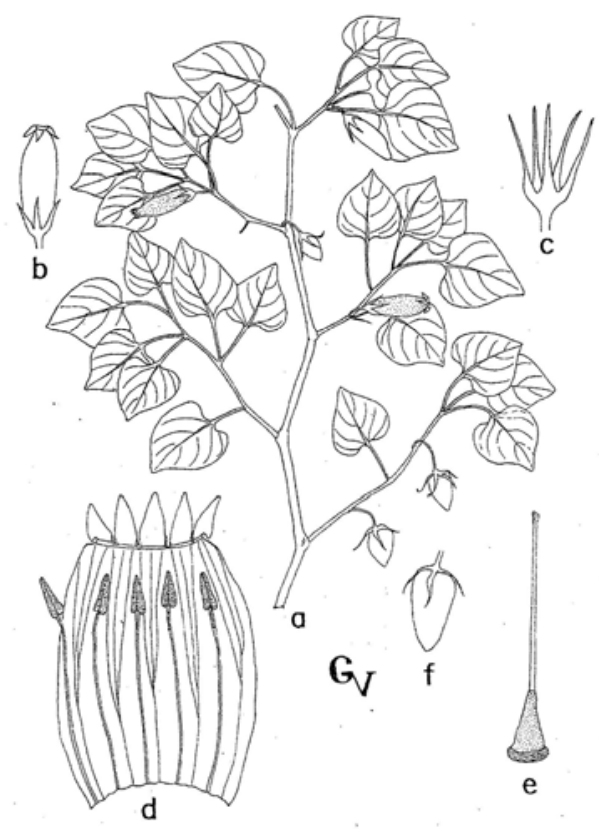

Fig. 9 Salpichroa ramosissima Miers

a) rama con flores y frutos $(x 1)$; b) flor $(x 2)$; c) cáliz (x5); d) corola desplegada (x5); e) pistilo $(x 5)$; f) fruto $(x 1)$

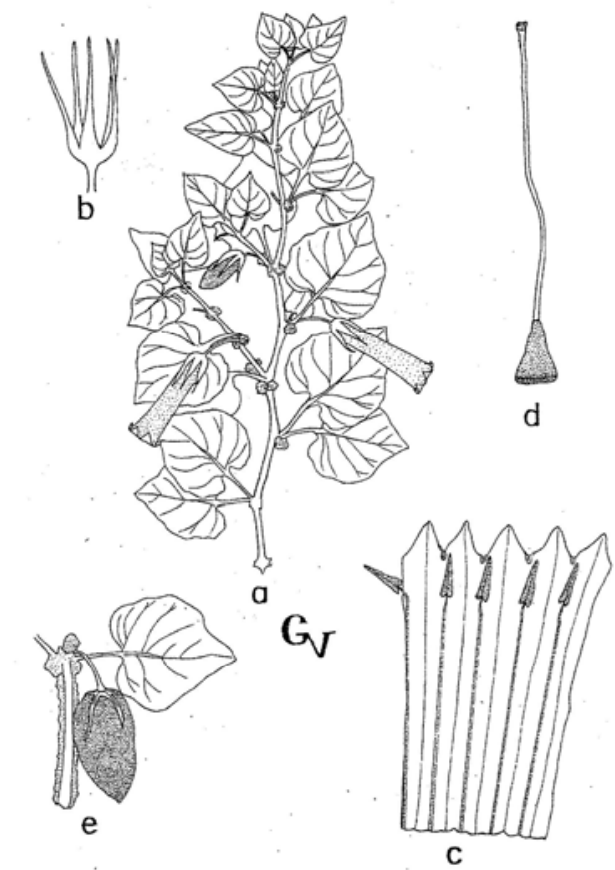

Fig. 8 Salpichroa microloba Keel

a) rama florida ( $x 1)$; b) cáliz (x3); c) corola desplegada (x3) ; d) pistilo (x3); e) fruto (x1).

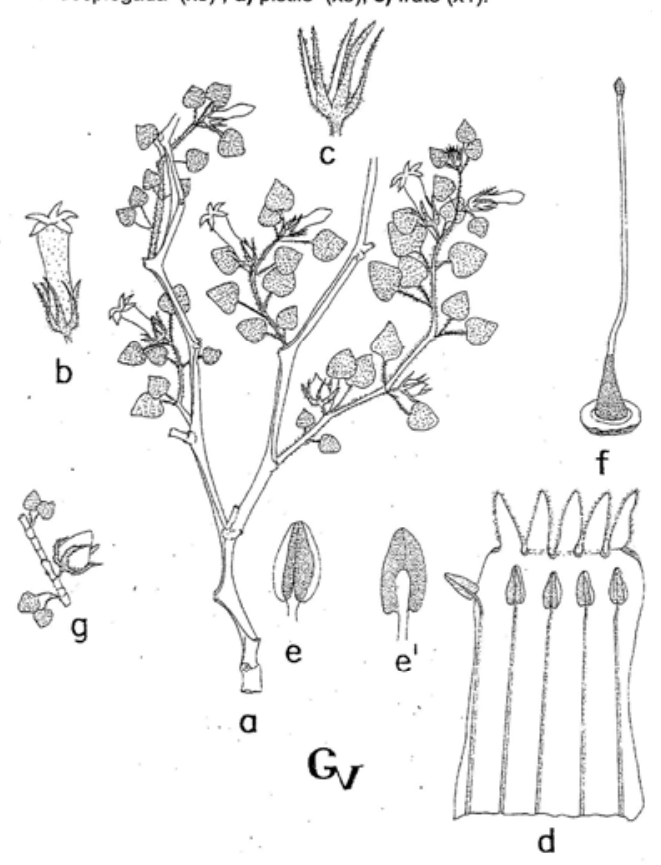

Fig. 10 Salpichroa tristis Miers var. lehmannii

a) rama florida $(x 1)$; b) flor $(x 2)$; c) cáliz ( $\times 3)$; d) corola desplegada $(x 5)$; e) antera vista ventral $(x 10)$; $\left.e^{\prime}\right)$ vista dorsal (x10); f) pistilo (x5); g) fruto (x1)

\footnotetext{
${ }^{1}$ Lugar donde se realizó el trabajo: Herbario del Departamento Académico de Biología de la Universidad Nacional Agraria La Molina, Av. La Molina s/n La Molina, Lima - Perú. Correo electrónico: g_vilcapoma@hotmail.com
} 